\title{
Study of the Compression Resistance of a Geopolymer Based Composite with Added Jute Fiber
}

\author{
Gustavo Lopes, Vicente Paes, João Dos Santos and Lais Alves*
}

Federal Center of Technological Education, Brazil

ISSN: 2576-8840

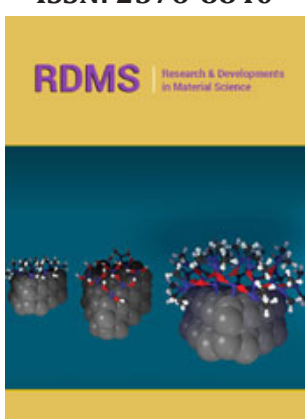

*Corresponding author: Lais Alves, Federal Center of Technological Education, Brazil

Submission: 幽 November 21, 2019

Published: 僵 December 02, 2019

Volume 12 - Issue 3

How to cite this article: Gustavo $\mathrm{L}$ Vicente P, João Dos S, Lais Alves. Study of the Compression Resistance of a Geopolymer Based Composite with Added Jute Fiber. Res Dev Material Sci. 12(3). RDMS.000788.2019.

DOI: 10.31031/RDMS.2019.12.000788

Copyright@ Lais Alves, This article is distributed under the terms of the Creative Commons Attribution 4.0 International License, which permits unrestricted use and redistribution provided that the original author and source are credited.

\begin{abstract}
Due to the need for new technologies that reduce the negative impact on the environment, the geopolymers, aluminosilicate-based materials, appear as a good alternative to Portland cement for having good mechanical properties, such as high initial strength. The objective of this work was to analyze the behavior of industrial geopolymer composites with the addition of jute fibers, according to the curing time of the material and the amount of fiber inserted, trying to identify if their use could bring benefits in the mechanical properties of the composite. Compression tests were made, and the results showed that the fibrous reinforced geopolymer composites have brought a good compatibility between fiber and matrix, showing a good mechanical behavior. The addition of the fibers allowed a greater ability of the composite to resist the loads after cracking, increasing its ductility. In addition to the increased deformation, there was also an increase in the compressive strength of the material.
\end{abstract}

Keywords: Geopolymers; Composites; Jute fibers; Compressive strength

\section{Introduction}

The preservation of the environment is a very important topic that has been gaining adherents after the industrial revolution. Global warming, burning, melting glaciers, climate change, pollution and major natural disasters in general are some examples of impacts that have raised the concern of large groups of people about the world we live in. Therefore, it is necessary to identify the actions and products used that contribute to this degradation and look for alternatives to reduce the risks to the planet, aiming to improve harmony with nature in the present and in the future. In construction, concrete is one of the most widely used substances in the world and requires large amounts of Portland cement, which produces large amounts of carbon dioxide $\left(\mathrm{CO}_{2}\right)$. Thus, with this very significant detriment to the environment, comes the importance of innovative and alternative ways of substituting this material [1]. Geopolymers appear as an alternative option that not only offers less risk to the environment, but also has good mechanical properties that make them a building material of great need for future study and projection [2]. The production of the geopolymers is through a reaction composed of a solid phase, called precursor, and a liquid phase, known as activator [3]. The precursor is characterized by reactive aluminosilicate materials, frequently used metakaolin and fly ash. The activator is composed of an alkaline solution, usually sodium hydroxide $(\mathrm{NaOH})$ or potassium hydroxide $(\mathrm{KOH})$. In general, regardless of the aluminosilicate material used, the macroscopic characteristics of the product will be similar [4]. Geopolymeric cement is a mixture based on polysiloxosialate, which is an aluminosilicate (Al-Si-O), sodium, potassium and calcium ( $\mathrm{Na}, \mathrm{K}, \mathrm{Ca}-\mathrm{PSS}$ ) compound and has high mechanical strength, durability and surface hardness [3]. Based on the composition and aggregates used, it is able to acquire other properties such as higher initial resistance [2], chemical resistance and refractoriness [4]. The use of fibrous reinforcement in geopolymer composites aims to obtain better properties for composites [5]. Due to their low cost and easy production, natural fibers began to be more researched, aiming to provide better properties for the material [6].

To prove the quality of the material, whether or not reinforced with fibers, testing is advisable. Compression testing is relatively easy to be realized and it is obtained the compressive strength that is a property that is almost always specified in projects, especially 
in the area of construction. In addition, various properties of concrete can be deduced from compressive strength such as modulus of elasticity, impermeability and durability [7]. This research aims to analyze the mechanical properties of geopolymers from laboratory tests. At the first stage, compression tests were performed for three cylindrical specimens without fiber addition. For the second stage, compression tests were performed for twovariable geopolymer composites. The first variable was the cure time, using three different specimen ages ( 1 day, 7 days and 14 days). The second variable was the amount of fiber added, used to analyze the efficiency of jute fiber, aiming to perform geopolymer composites tests in three distinct percentages of fiber addition $(0 \%$, $1 \%$ and $2 \%$ of fiber volume in the mixture). Thus, it was aimed to acquire a better basis for study and develop a better investigation of the mechanical responses, both for the variation of the geopolymer age and for the influence of the amount of fibers added, comparing later with results obtained in other studies involving concretes. By analyzing the mechanical properties of geopolymer, its viability can be determined, relative to other materials.

\section{Materials and Methods}

The material used in this work was the Cement GP-1818 geopolymer from Geo-Pol ${ }^{\circledR}$ (São Paulo, Brazil). After proper preparation and demolding of the material, it was observed that the material specimens (CP) prepared with both types of mold (aluminum and PVC) were very damaged. Due to the condition of the specimens of this material, a new industrial geopolymer, was provided for the essays to be performed. The supplier (same as the previous material) informed that the new material has a more advanced binder formulation, with ingredients that improve its performance and guarantee better properties after cure, but with similar powder/liquid ratios compared to the GP-1818. A chemical analysis was performed for the comparison of both materials. With the results, it was observed that the main difference between the materials is that the new one has a higher $\mathrm{Si} / \mathrm{Al}$ ratio and does not contain calcium, as described in Table 1 . In order to respect the proportion of approximately $75 \mathrm{~g}$ of precursor powder per $100 \mathrm{~g}$ of activating liquid, the material required to fill the molds for specimen preparation was calculated and, using a digital precision balance of up to $0.01 \mathrm{~g}$ and with a maximum supported load of $510 \mathrm{~g}$, the amount of material was separated and measured. According to the calculations, the ideal amount of precursor powder for the production of geopolymer paste would be approximately $187.09 \mathrm{~g}$ For the activating liquid, $249.47 \mathrm{~g}$ would be required. However, as noted in other works, small variations are acceptable as they would not be sufficient to significantly alter the properties of the geopolymer. The geopolymer paste was then prepared with the aid of a mechanical stirrer with a maximum speed of 3000RPM. The material was mixed for 2 minutes at 900RPM (30\%). After this time, the machine was stopped so that dust residues on the sides of the container are scraped off and added to the mix again. Then the material was again mixed at a higher speed of 1500RPM (50\%) for a further 2 minutes.
Table 1: Chemical composition of materials.

\begin{tabular}{|c|c|c|}
\hline Component & GP-1818 & New Material \\
\hline $\mathrm{Al}_{2} \mathrm{O}_{3}$ & $14.10 \%$ & $11.90 \%$ \\
\hline $\mathrm{SiO}_{2}$ & $29.40 \%$ & $32.30 \%$ \\
\hline $\mathrm{K}_{2} \mathrm{O}$ & $13.31 \%$ & $16.80 \%$ \\
\hline $\mathrm{CaO}$ & $3.50 \%$ & $0 \%$ \\
\hline
\end{tabular}

The fibers used are made with $100 \%$ jute. It was first cut to a length of $50 \mathrm{~mm}$, but the workability of the material worsened considerably. So, it was thought to use a smaller size. Picanço and Ghavami [8] concluded that a better performance of Curauá fibers in the compressive behavior of mortars were cut with $25 \mathrm{~mm}$ in length and, therefore, it was decided to use this same length for the jute fibers in the present work. After cutting, the fibers were weighed on the digital scale. Fidelis [9] studied various properties of jute, and because it is a study using national materials, the density of jute fiber used in this work was $1.61 \mathrm{~g} / \mathrm{cm}^{3}$, value obtained by the author.

Considering this density, the amount of fiber to be used was calculated and added based on the volume of material required to fill the mold. Regarding the amount of fibers, the specimens were prepared without fiber, with $1 \%$ and $2 \%$ of the volume of material in jute fibers, which represented approximately $3 \mathrm{~g}$ and $6 \mathrm{~g}$, respectively. For the preparation of the composite, the fibers were slowly added to the geopolymer and mixed slowly and manually to prevent them from becoming completely concentrated. As the fibers were added, the workability of the material became significantly worse, making it difficult to handle the mix and place it in the molds. The tests were performed on the MTS model 311.11 universal testing machine with a $1000 \mathrm{kN}$ load capacity and a speed of $0.2 \mathrm{~mm} / \mathrm{min}$. During its performance, supported load and displacement data are obtained for further analysis.

\section{Results and Discussion}

The identification model used for the specimens was CP-XF YD, where CP was defined as specimen, $X$ the fiber percentage (F) and $Y$ the cure time in days (D). Table 2 shows the maximum load values ( $\mathrm{F}$ in $\mathrm{kN}$ ) obtained in the compression test and the maximum stress (fc) calculated for specimens without fiber, with $1 \%$ and $2 \%$ of volume of jute fiber material, respectively. Actual strain values $(\varepsilon)$ were obtained. The values for initial real strain to the maximum stress point ( $\varepsilon \mathrm{i}$ ), the actual body strain to the moment of rupture ( $\varepsilon r)$ and the ratio of these values can also be observed in Table 2. The results obtained in the test for 1-day curing can be seen in Figure 1. In the graph, it is possible to observe the advantages obtained by inserting the jute fiber in the geopolymer matrix. The fiber bodies showed higher deformation capacity before rupture, as expected. However, it is possible to observe that the load required for material failure increased proportionally with the amount of fibers, unlike that observed in other researches, such as Picanço and Ghavami [8], which shows that the insertion of jute fibers in a mortar-based cementitious material reduced its compressive strength and that of 
Frayyeh and Swaif [10], showing that the addition of carbon fibers above $1 \%$ of the mixture also began to show reduced compressive strength. Although CP-2F1D supported a higher load, it is noticeable that CP-1F1D presented a larger deformation than the others, with $\varepsilon r=2.13 \%$. It is likely that this behavior can be attributed to a better fiber distribution in the geopolymer matrix. CP-0F1D achieved not only the lowest strength but also the lowest strain rate.

Table 2: Fiber free geopolymer results.

\begin{tabular}{|c|c|c|c|c|c|c|}
\hline CP & $\begin{array}{l}\text { Curing } \\
\text { (days) }\end{array}$ & $F(k N)$ & $\mathrm{f}_{\mathrm{c}}(\mathrm{MPa})$ & $\varepsilon_{\mathrm{i}}(\%)$ & $\varepsilon_{\mathrm{r}}(\%)$ & $\varepsilon_{\mathrm{i}} / \varepsilon_{\mathrm{r}}(\%)$ \\
\hline CP-0F1D & 1 & 17.84 & 9.86 & 1.15 & 1.38 & 83.61 \\
\hline CP-0F7D & 7 & 19.59 & 10.82 & 1.42 & 1.51 & 94.18 \\
\hline CP-0F14D & 14 & 23.95 & 11.69 & 1.58 & 1.71 & 92.39 \\
\hline CP-1F1D & 1 & 34.02 & 18.8 & 1.54 & 2.13 & 72.16 \\
\hline CP-1F7D & 7 & 47.59 & 26.3 & 1.17 & 1.64 & 71.43 \\
\hline CP-1F14D & 14 & 53.99 & 29.84 & 0.95 & 1.18 & 79.84 \\
\hline CP-2F1D & 1 & 44.15 & 24.4 & 1.12 & 1.69 & 65.94 \\
\hline CP-2F7D & 7 & 52.89 & 29.23 & 1.04 & 1.99 & 52.34 \\
\hline CP-2F14D & 14 & 48.69 & 26.91 & 1.07 & 1.69 & 63.65 \\
\hline
\end{tabular}

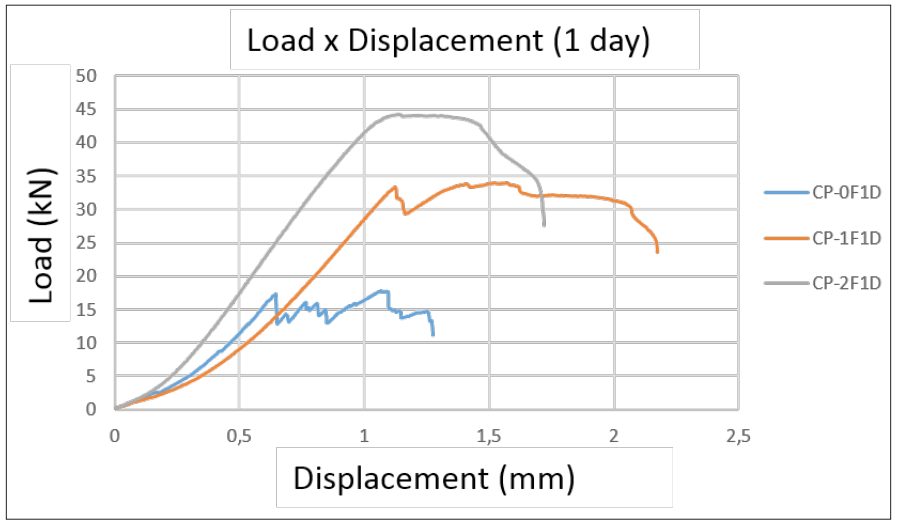

Figure 1: Graph load $\mathrm{x}$ displacement of bodies with 1 day of curing.

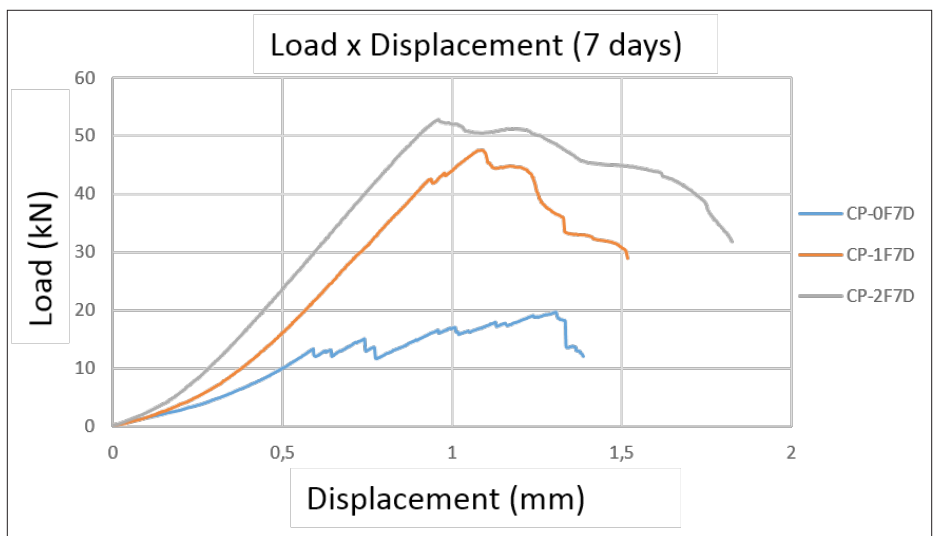

Figure 2: Graph load $\mathrm{x}$ displacement of bodies with 7 days of curing.

For 7 day curing specimens, the results obtained in the test can be seen in Figure 2. CP-0F7D showed similar behavior to that observed in CP-0F1D, with a small increase in its resistance, but the cracking was noticeable in the body structure soon after reaching full load. However, unlike the previous graph, CP-2F7D showed higher final deformation capacity than CP-1F7D, with a deformation of $\varepsilon r=1.99 \%$. This probably shows us the efficiency of jute fiber to withstand stresses and hold the material longer. Both fiber bodies 
continue to exhibit better creep rates and higher compressive strength and continue to resist the applied loads after cracking after reaching the frame boundary. Figure 3 shows the data from the 14 days curing specimens, with the exception of CP-0F14D, which presented a significant crack after demolding and fell apart before the essay. Nevertheless, the higher fiber volume was more efficient in the deformation capacity, also observed in the 7 days specimens. Another observation about CP-1F14D is that it was the specimen with the lowest strain rate and the smallest displacement among the tested bodies [11], with $\varepsilon r=1.18 \%$. It is possible that this characteristic is due to the fibers detaching from the matrix after the cracking started, when reaching the maximum stress supported by the composite.

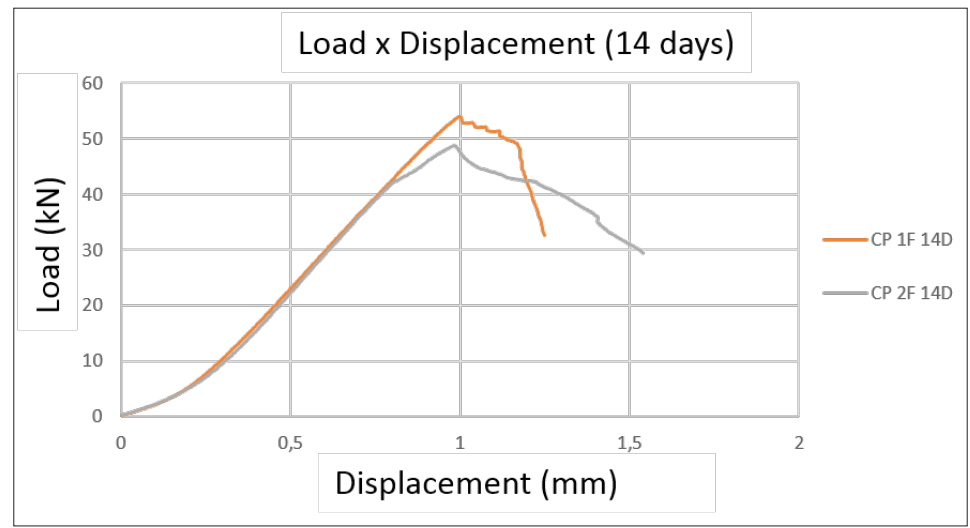

Figure 3: Graph load x displacement of bodies with 14 days of curing.

In general, considering the ratio of deformation values $\varepsilon$ i and er presented, it can be observed that the specimens containing the largest volume of fiber were actually able to withstand the load longer. Specimens with $2 \%$ fiber showed the best results, demonstrating that they reached only $52 \%$ to $66 \%$ of their final deformation when reaching the maximum stress [12]. This is as expected, considering that the specimens without fiber have the lowest deformation ratio, with values of $83 \%$ and $94 \%$.

Figure 4 presents the compassion of the results in 1, 7 and 14 days for specimens without fibers (blue), 1\% of fibers (orange) and $2 \%$ of fibers (gray). From Figure 4 , it is possible to notice that the materials with $1 \%$ and $2 \%$ of fiber acquired in 1 day of cure about $60.0 \%$ and $83.5 \%$, respectively, of their maximum strength found with an older age. This proves the quality of the geopolymer composite in acquiring great initial strength even with the insertion of jute fibers, showing that they do not have great interference in this property. Although the fiber-free material did not show great strength, showing some fragility, its percentage of initial resistance compared to that found in 7 days was $91.13 \%$.

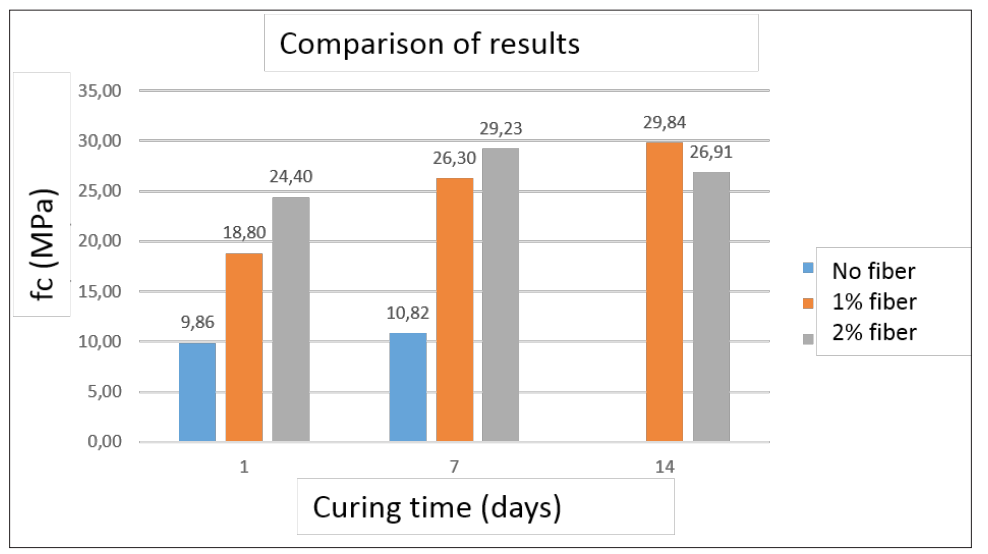

Figure 4: Comparison of stress $x$ curing time results of specimens.

\section{Final Considerations}

It is noted that the insertion of jute fibers in the geopolymer composites brought an increase of the compressive strength in relation to the non-fiber composites analyzed, reducing the material fragility. In addition, the fibers were able to change the composites rupture mode and improve their ductility and toughness, allowing for an increase in their ability to deform and resist load after cracking, which is not the case in non-fiber material.
It is believed that the fragility zone found in CP-2F14D occurred due to an unbalanced fiber concentration inside the specimen, which negatively affected the maximum resistance found. Therefore, analyzing all these factors, it can be said that there was a good compatibility between fiber and matrix, since the material visually showed that it supported well the efforts, maintaining a good part of its shape, besides acquiring better strength and deformation gains according to with the results obtained in the tests performed. 


\section{References}

1. Provis J L (2014) Geopolymers and other alkali activated materials: why, how, and what? Materials and Structures 47(1-2): 11-25.

2. Provis J L, Jannie S J (2009) Geopolymers: structures, processing, properties and industrial applications. Elsevier.

3. Giannopoulou L, Panias D (2007) Structure, design and applications of geopolymeric materials. Proceedings of the $3^{\text {rd }}$ international conference on deformation processing and structure of materials. Serbia, pp. 5-15.

4. Lais A, Arissa N, João d S, Silvio de B (2019) A quick overview on geopolymer chemistry and general properties. Res Dev Material Sci 12(2): 1249-1251.

5. Davidovits J (1994) Properties of geopolymer cements. Alkaline cements and concretes, Ukrânia, pp. 131-149.

6. Borges PH, Paulo H, Lourenco TM, Foureaux AFS (2014) Comparative study of the life cycle assessment of geopolymer concrete and CP-I Portland cement concrete. Ambient constr 14(2): 153-168.
7. Moe T, Kin L (2002) Effects of environmental aging on the mechanical properties of bamboo-glass fiber reinforced polymer matrix hybrid composites. Composites Part A: Applied Science and Manufacturing 33: 43-52.

8. Saheb DN, Jog JP (1999) Natural fiber polymer composites: A review. Adv in Polymer Techn 18(4): 351-363.

9. Metha PK, Monteiro PJ (2006) Concrete: Microstructure, properties, and materials. ( $3^{\text {rd }}$ edn), McGraw-Hill Publishing, New York, USA.

10. Picanço MS, Ghavami K (2008) Compression behavior of vegetable fiber reinforced mortars from the Amazon (in Portuguese). REM: R Esc Minas, Ouro Preto 61(1): 13-18.

11. Fidelis ME (2014) Development and mechanical characterization of jute fiber reinforced textile cement composites (in Portuguese). Thesis, PEC/ COPPE/UFRJ.

12. Frayyeh Q, Swaif A (2018) Mechanical properties of fly ash geopolymer mortar reinforced with carbon fibers. 